\title{
Measuring trauma severity using the 1998 and 2005 revisions of the Abbreviated Injury Scale*
}

\author{
MENSURAÇÃO DA GRAVIDADE DO TRAUMA COM AS VERSÕES 1998 E 2005 DA \\ ABBREVIATED INJURY SCALE
}

\author{
LA MEDICIÓN DE LA GRAVEDAD DEL TRAUMA CON LAS VERSIONES DE LA \\ ABBREVIATED INJURY SCALE DE 1998 Y 2005
}

Maria Carolina Barbosa Teixeira Lopes ${ }^{1}$, Iveth Yamaguchi Whitaker ${ }^{2}$

\begin{abstract}
Objectives: This study aims to compare injury and trauma severity as measured by the 1998 and 2005 revisions of the Abbreviated Injury Scale and to determine the mortality in the Injury Severity Score and the New Injury Severity Score in both versions. Method: This cross-sectional retrospective study analyzed injuries of trauma patients from three university hospitals in São Paulo, Brazil. Each injury was coded using the Abbreviated Injury Scale 1998 and 2005. The statistical tests applied were the Wilcoxon, McNemar-Bowker, Kappa, and $Z$ tests. Results: Comparing the two versions resulted in significant disagreement regarding the scores of certain body regions. With the 2005 version, injury and trauma severity levels were significantly decreased, and the mortality was higher at lower scores. Conclusion: Injury and trauma severity were decreased and the percentage mortality was changed when the 2005 revision of the Abbreviated Injury Scale was used.
\end{abstract}

\section{DESCRIPTORS}

Wounds and injuries

Trauma severity indices

Abbreviated Injury Scale

Hospital mortality

Emergency nursing

\section{RESUMO}

Objetivo: Comparar a gravidade das lesões e do trauma mensurada pelas versões da Abbreviated Injury Scale 1998 e 2005 e verificar a mortalidade nos escores Injury Severity Score e New Injury Severity Score nas duas versões. Método: Estudo transversal e retrospectivo analisou lesões de pacientes de trauma, de três hospitais universitários do município de São Paulo, Brasil. Cada lesão foi codificada com Abbreviated Injury Scale 1998 e 2005. Os testes estatísticos aplicados foram Wilcoxon, $\mathrm{McNe}$ mar-Bowker, Kappa e teste Z. Resultados: A comparação das duas versões resultou em discordância significante de escores em algumas regiões corpóreas. Com a versão 2005 os níveis de gravidade da lesão e do trauma foram significantemente reduzidos e a mortalidade foi mais elevada em escores mais baixos. Conclusão: Houve redução da gravidade da lesão e do trauma e alteração no percentual de mortalidade com o uso da Abbreviated Injury Scale 2005.

\section{RESUMEN}

Objetivo: Comparar la gravedad de las lesiones y del trauma evaluados por medio de las versiones de 1998 y 2005 de la Abbreviated Injury Scale y verificar el porcentaje de mortalidad por medio del Injury Severity Score y el New Injury Severity en las dos versiones. Método: Estudio transversal retrospectivo que analizó las lesiones de trauma de los pacientes en tres hospitales universitarios del municipio de São Paulo, Brasil. Cada lesión fue codificada de acuerdo a la Abbreviated Injury Scale de 1998 y 2005. Las pruebas estadísticas utilizadas fueron de Wilcoxon, McNemar-Bowker, Kappa y la prueba Z. Resultados: En la comparación de las dos versiones, se obtuvo una diferencia significativa de los puntajes en algunas regiones corporales. Con la versión de 2005 los niveles de gravedad de la lesión y del trauma fueron significativamente más bajos y la mortalidad fue mayor en las puntuaciones más bajas. Conclusión: Hubo una reducción en la gravedad de la lesión y del trauma y cambio en el porcentaje de mortalidad con el uso de la Abbreviated Injury Scale 2005.

\author{
DESCRITORES \\ Ferimentos e lesões \\ Índices de gravidade do trauma \\ Escala Resumida de Ferimentos \\ Mortalidade hospitalar \\ Enfermagem em emergência
}

\author{
DESCRIPTORES \\ Heridas y traumatismos \\ Índices de gravedad del trauma \\ Escala Resumida de Traumatismos \\ Mortalidad hospitalaria \\ Enfermería de urgencias
}

*Extracted from the thesis "Mensuração da gravidade do trauma com a Abbreviated Injury Scale: comparação entre as versões 1998 e 2005 [Trauma severity assessment with the Abbreviated Injury Scale: comparison of the1998 and 2005 versions]", Universidade Federal de São Paulo - UNIFESP, 2011. ${ }^{1}$ Master in Science, Escola Paulista de Enfermagem, UNIFESP, São Paulo, SP, Brazil. ${ }^{2}$ Ph.D. in Nursing, Escola Paulista de Enfermagem, UNIFESP, São Paulo, SP, Brazil. 


\section{INTRODUCTION}

The Abbreviated Injury Scale (AIS) is the most widely used anatomy-based instrument to measure the severity of traumatic injuries ${ }^{(1-3)}$. This system has existed since $1971^{(2,4-5)}$ and is being reviewed by the Association for the Advancement of Automotive Medicine ${ }^{(3,6-7)}$. The overall severity of multiple injuries can be determined from the AIS classification of each injury by calculating the Injury Severity Score(ISS) ${ }^{(6-10)}$ and the New Injury Severity Score (NISS) ${ }^{(5,10)}$.

ISS is obtained based on the sum of the squares of the higher AIS scores in three different body regions ${ }^{(6-9)}$. The scores range from 1 to 75, and higher scores indicate greater trauma severity. NISS has been proposed as a modification of the ISS to correct limitations and improve accuracy $^{(5)}$. NISS is obtained by the sum of the squares of the highest three AIS scores regardless of the body region.

The updating of the AIS over time has allowed the characterization of trauma epidemiology and comparison of the results of the care provided. However, when the AIS was updated from the 1998 to the 2005 version, there was a significant change in scores for certain body regions.

In general, the severity scores for brain injuries underwent important modifications. Intracranial hematomas scores were decreased by one point. Subarachnoid hemorrhage, previously classified as score 3, was reclassified as score 2 . In the thoracic region, the rib fracture coding was simplified in the 2005 version. Pneumothorax and hemothorax became scored separately. Certain thoracic injuries had increased AIS scores; i.e., they were considered more severe in the 2005 version. New codes regarding choking, drowning/suffocation, hypothermia, and injury by caustic agents were included. Moreover, among the new coding rules, the principle of bilaterality was expanded to certain specific injury descriptors ${ }^{(6,7)}$.

Given the changes in the AIS-05 version, there was a concern about the impact of these changes for measuring trauma severity, especially when comparing the results of different services that used different AIS versions.

Thus, this study was conducted to answer the question Does the AIS-05 version modify injury and trauma severity level compared to the 1998 version?. The study aimed to compare the injury (AIS score) and trauma (ISS and NISS) severity as determined by the AIS-98 and AIS05 versions and to determine the mortality in the ISS and NISS in both versions.

\section{METHOD}

In this cross-sectional retrospective study, the sample consisted of trauma victims with the following inclusion criteria: involvement in events categorized in
Chapter XX -External Causes of Morbidity and Mortality under headings V01 to Y35 of the International Statistical Classification of Diseases and Related Health Problems and treatment in the emergency room (ER) and hospitalization in teaching hospitals located in the city of São Paulo/Brazil (Hospital São Paulo /Universidade Federal de São Paulo (UNIFESP), Hospital das Clínicas/ Faculdade de Medicina da Universidade de São Paulo e Irmandade da Santa Casa de Misericórdia de São Paulo/ Faculdade de Ciências Médicas) from June 1 to November 30, 2005. Patients treated at the ER due to manifestation of complications resulting from traumatic injury, to complement the treatment, or to treat sequelae were excluded. Data were collected retrospectively in hospitals and in the Forensic Medical Institute after obtaining authorization from the Secretaria de Segurança Pública do Estado de São Paulo and approval of the research project by the UNIFESP Research Ethics Committee (CEP 0089/09).

All anatomical injuries obtained from patients' medical records and the autopsy findings on patients who died were manually classified according to AIS-98 and AIS-05, and trauma severity was defined by calculating ISS and NISS. The ISS and NISS scores were grouped into the following ranges: 1 to 8,9 to 15,16 to 24,25 to 40,41 to 49 , 50 to 74 , and 75. Analysis of in-hospital mortality in the ISS and NISS scores was performed considering the score of 16 as the cutoff point, as ISS $\geq 16$ corresponds to major trauma with mortality greater than $10 \%$, and the victim needs to be assisted in a trauma center ${ }^{(8)}$.

Data were entered into a spreadsheet and doublechecked by two professionals to correct possible typing errors. The Wilcoxon test ${ }^{(11)}$ was used to compare the scores of the AIS-98 and AIS-05 versions according to body regions, as well as to compare the ISS and NISS means calculated using both AIS versions. The McNemar-Bowker and Kappa tests(12-13) were used to compare the AIS-98 and AIS-05 scores according to AIS severity levels and to compare the ISS and NISS scores obtained for each version, according to severity ranges. The standardized residual, expressed in standard deviation (SD) units, was used to determine which categories contributed to the association between two variables. Values greater than 1.96 or lower than -1.96 defined excess or lack of occurrence, respectively ${ }^{(14)}$. The $Z$ test was used to compare the frequency of deaths in the ISS and NISS scores $<16$ derived from AIS-98 and AIS-05 ${ }^{(14)}$. Statistical tests were performed assuming a significance level of 0.05 .

\section{RESULTS}

The total number of patients selected according to the inclusion criteria was 721 . The mean age was 35.80 years ( $S D=19.68)$, with a predominance of males $(80.20 \%)$. The most common mechanism of trauma was blunt $(82.70 \%)$,
Measuring trauma severity using the 1998 and 2005 revisions of the Abbreviated Injury Scale Lopes MCBT, Whitaker IY 
followed by penetrating (14.80\%) and others such as burns and exposure to electric current (2.50\%). The in-hospital mortality was $16.36 \%$. To analyze injury and trauma severity, of the total 721 patients, seven $(0.97 \%)$ were excluded because they had injuries coded as unknown severity by AIS (AIS 9) or because they exhibited descriptions not predicted in the AIS manual (swelling in the knee, upper or lower extremities).

The total number of injuries was 2,999, with 2,970 coded by the 1998 version and 2,999 coded by the 2005 version. The difference between the number of injuries in the two AIS versions referred to 29 thoracic injuries coded only by AIS-05. Of the total 2,970 injuries, 539 (18.15\%) had different AIS-98 and AIS-05 scores. Decreased AIS scores were observed for 520 (17.51\%) injuries, and increased scores were observed for 19 (0.64\%) injuries.

The data in Table 1 show that there was a substantial agreement (Kappa 0.798) between scores assigned to injuries coded by AIS-98 and AIS-05. Disagreement between scores $(p<0.001)$ was observed at all injury severity levels, except for AIS 6 score. For the AIS 4 (severe) score, there was a higher frequency of injuries classified as severe in the 1998 version that were classified as serious (74.70\%) in AIS-05. Fewer differences were observed in serious injuries in AIS-98. The analysis showed that $24.55 \%$ were classified as moderate (AIS 2 ) in the AIS-05 version. Moreover, $35.85 \%$ of injuries classified as critical (AIS 5) according to AIS-98 were coded as severe in AIS-05.

Table 1. Distribution of injuries according to AIS-98 and AIS-05 severity scores. São Paulo- SP, 2005

\begin{tabular}{|c|c|c|c|c|c|c|c|c|}
\hline \multirow[b]{2}{*}{ AIS-98 } & & \multicolumn{6}{|c|}{ AIS-05 } & \multirow[b]{2}{*}{ Total } \\
\hline & & $\begin{array}{l}\text { minor } \\
\text { (AIS 1) }\end{array}$ & $\begin{array}{c}\text { moderate } \\
\text { (AIS 2) }\end{array}$ & $\begin{array}{l}\text { serious } \\
\text { (AIS 3) }\end{array}$ & $\begin{array}{l}\text { severe } \\
\text { (AIS 4) }\end{array}$ & $\begin{array}{l}\text { critical } \\
\text { (AIS 5) }\end{array}$ & $\begin{array}{c}\text { maximal } \\
\text { (AIS 6) }\end{array}$ & \\
\hline minor & $\mathrm{n}$ & 1053 & 15 & & & & - & 1068 \\
\hline (AIS 1) & $\%$ & 98.60 & 1.40 & - & - & - & - & 35.96 \\
\hline moderate & $\mathrm{n}$ & 30 & 664 & 3 & - & - & - & 697 \\
\hline (AIS 2) & $\%$ & 4.30 & 95.27 & 0.43 & - & - & - & 23.47 \\
\hline serious & $\mathrm{n}$ & 3 & 189 & 578 & - & - & - & 770 \\
\hline (AIS 3) & $\%$ & 0.39 & 24.55 & 75.06 & - & - & - & 25.93 \\
\hline severe & $\mathrm{n}$ & - & 15 & 245 & 67 & 1 & - & 328 \\
\hline (AIS 4) & $\%$ & - & 4.57 & 74.70 & 20.43 & 0.30 & - & 11.04 \\
\hline critical & $\mathrm{n}$ & - & - & - & 38 & 68 & - & 106 \\
\hline (AIS 5) & $\%$ & - & - & - & 35.85 & 64.15 & - & 3.57 \\
\hline maximal & $\mathrm{n}$ & - & - & - & - & - & 1 & 1 \\
\hline (AIS 6) & $\%$ & - & - & - & - & - & 100.00 & 0.03 \\
\hline \multirow[t]{2}{*}{ Total } & $\mathrm{n}$ & 1086 & 883 & 826 & 105 & 69 & 1 & 2970 \\
\hline & $\%$ & 36.57 & 29.73 & 27.81 & 3.54 & 2.32 & 0.03 & 100.00 \\
\hline
\end{tabular}

McNemar-Bowker test $(p<0.001)$ and Kappa test $(p<0.001)=0.748$.

The comparison between the AIS-98 and AIS-05 scores assigned to injuries in each body region (Table 2) showed that the mean AIS-05 scores were significantly lower in the head $(p<0.001)$, thorax $(p<0.001)$, abdomen $(p<0.004)$, and upper extremities $(p<0.001)$. In the thoracic region, 29 injuries classified only by AIS05 (225 vs. 254) were observed because certain injuries are classified as single injuries in the 1998 version, such as pneumothorax and rib fractures, that were coded separately in AIS-05.

Table 2 - Distribution of injuries according to AIS scores in the 1998 and 2005 versions and body regions. São Paulo - SP, 2005

\begin{tabular}{|c|c|c|c|c|c|c|c|c|c|c|c|c|c|c|c|c|c|c|}
\hline \multicolumn{19}{|c|}{ AIS-98 and AIS-05 scores } \\
\hline & \multicolumn{2}{|c|}{ head } & \multicolumn{2}{|c|}{ face } & \multicolumn{2}{|c|}{ neck } & \multicolumn{2}{|c|}{ thorax } & \multicolumn{2}{|c|}{ abdomen } & \multicolumn{2}{|c|}{ spine } & \multicolumn{2}{|c|}{ UE* } & \multicolumn{2}{|c|}{$\mathbf{L E}^{* * *}$} & \multicolumn{2}{|c|}{ Unspecified } \\
\hline & 98 & 05 & 98 & 05 & 98 & 05 & 98 & 05 & 98 & 05 & 98 & 05 & 98 & 05 & 98 & 05 & 98 & 05 \\
\hline $\mathbf{n}$ & 1124 & 1124 & 452 & 452 & 32 & 32 & 225 & 254 & 210 & 210 & 89 & 89 & 310 & 310 & 487 & 487 & 41 & 41 \\
\hline $\mathbf{x}$ & 2.91 & 2.55 & 1.27 & 1.24 & 1.53 & 1.53 & 2.63 & 2.41 & 2.13 & 2.09 & 2.33 & 2.30 & 1.49 & 1.40 & 1.95 & 1.96 & 1.71 & 1.66 \\
\hline$\mu$ & 3 & 3 & 1 & 1 & 1 & 1 & 3 & 3 & 2 & 2 & 2 & 2 & 1 & 1 & 2 & 2 & 1 & 1 \\
\hline SD & 1.21 & 1.04 & 0.46 & 0.43 & 0.80 & 0.72 & 0.97 & 0.90 & 0.96 & 0.95 & 0.78 & 0.78 & 0.63 & 0.52 & 0.84 & 0.83 & 1.29 & 1.26 \\
\hline Min & 1 & 1 & 1 & 1 & 1 & 1 & 1 & 1 & 1 & 1 & 1 & 1 & 1 & 1 & 1 & 1 & 1 & 1 \\
\hline $\operatorname{Max}$ & 5 & 5 & 3 & 3 & 4 & 3 & 5 & 5 & 5 & 5 & 5 & 5 & 3 & 3 & 5 & 5 & 6 & 6 \\
\hline $\mathbf{P}^{\#}$ & \multicolumn{2}{|c|}{$<0.001$} & \multicolumn{2}{|c|}{0.084} & \multicolumn{2}{|c|}{0.317} & \multicolumn{2}{|c|}{$<0.001$} & \multicolumn{2}{|c|}{0.004} & \multicolumn{2}{|c|}{1.000} & \multicolumn{2}{|c|}{0.001} & \multicolumn{2}{|c|}{0.470} & \multicolumn{2}{|c|}{0.157} \\
\hline
\end{tabular}

*UE: upper extremities; **LE: lower extremities. \# Wilcoxon test

According to Table 3, the mean ISS and NISS derived from AIS-05 were significantly lower $(p<0.001)$ than the values calculated based on AIS-98. The mean ISS decreased from
15.22 (AIS-98) to 12.66 (AIS-05), and the median decreased from 14 to 10 . The mean NISS decreased from 20.86 (AIS-98) to 17.21 (AIS-05), and the median decreased from 17 to 14 . 
Table 3 - ISS and NISS values according to the AIS-98 and AIS05 versions. São Paulo - SP, 2005

\begin{tabular}{lcccccc}
\hline & Mean & Median & SD & Min & Max & P value \\
\hline ISS98 & 15.22 & 14 & 10.38 & 1 & 75 & $<0.001$ \\
ISS05 & 12.66 & 10 & 9.151 & 1 & 75 & \\
NISS98 & 20.86 & 17 & 14.78 & 1 & 75 & $<0.001$ \\
NISS05 & 17.21 & 14 & 12.19 & 1 & 75 & \\
\hline
\end{tabular}

Wilcoxon test.

The data in Table 4 show the percentage of agreement and disagreement of the ISS scores calculated based on the two AIS versions analyzed in this study.
The percentages of agreement of the ISS scores were significant in all severity ranges because the standardized residual values were greater than 1.96, and the Kappa showed moderate agreement of $0.575(p<0.001)$. However, in all severity ranges except ISS 75, there was a significant disagreement between the ISS scores obtained with AIS-98 and AIS05 (McNemar-Bowker test $\mathrm{p}<0.001$ ). In the severity ranges that include ISS scores from 16 to 24 and from 41 to 49 , the percentage of disagreement between scores was higher than the percentage of agreement $(72.92 \%$ and $75.00 \%$ vs. $27.08 \%$ and $25.00 \%$, respectively). Despite the occurrence of discrepant ISS scores at the severity ranges from 1 to 8 and from 9 to 15 , the standardized residuals were low (less than -1.96 ).

Table 4 - Distribution of ISS scores according to the AIS-98 and AIS-05 versions and severity ranges. São Paulo - SP, 2005.

\begin{tabular}{|c|c|c|c|c|c|c|c|c|c|}
\hline \multirow{2}{*}{ ISS 98} & & \multicolumn{7}{|c|}{ ISS 05} & \multirow{2}{*}{ Total } \\
\hline & & 1 to 8 & 9 to 15 & 16 to 24 & 25 to 40 & 41 to 49 & 50 to 74 & 75 & \\
\hline \multirow[t]{3}{*}{1 to 8} & $\mathrm{n}$ & 163 & 2 & - & - & - & - & - & 165 \\
\hline & $\%$ & 98.79 & 1.21 & - & - & - & - & - & 100.00 \\
\hline & St. Res.* & 24.2 & -12.9 & -6 & -5.7 & -1.2 & -1 & -0.5 & \\
\hline \multirow[t]{3}{*}{9 to 15} & $\mathrm{n}$ & 23 & 179 & - & - & - & - & - & 202 \\
\hline & $\%$ & 11.39 & 88.61 & - & - & - & - & - & 100.00 \\
\hline & St. Res.* & -5.6 & 14.7 & -6.9 & -6.5 & -1.4 & -1.1 & -0.6 & \\
\hline \multirow[t]{3}{*}{16 to 24} & $\mathrm{n}$ & - & 140 & 52 & - & - & - & - & 192 \\
\hline & $\%$ & - & 72.92 & 27.08 & - & - & - & - & 100.00 \\
\hline & St. Res.* & -9.6 & 9 & 5.8 & -6.3 & -1.4 & -1.1 & -0.6 & \\
\hline \multirow[t]{3}{*}{25 to 40} & $\mathrm{n}$ & 0 & 1 & 51 & 87 & 1 & - & - & 140 \\
\hline & $\%$ & - & 0.71 & 36.43 & 62.15 & 0.71 & - & - & 100.00 \\
\hline & St. Res.* & -7.8 & -11.8 & 8.1 & 19.2 & 0 & -0.9 & -0.5 & \\
\hline \multirow[t]{3}{*}{41 to 49} & $\mathrm{n}$ & - & - & 1 & 5 & 2 & - & - & 8 \\
\hline & $\%$ & - & - & 12.50 & 62.50 & 25.00 & - & - & 100.00 \\
\hline & St. Res.* & -1.7 & -2.6 & -0.2 & 4.2 & 8.3 & -0.2 & -0.1 & \\
\hline \multirow[t]{3}{*}{50 to 74} & $\mathrm{n}$ & - & - & - & 1 & 2 & 3 & - & 6 \\
\hline & $\%$ & - & - & - & 16.67 & 33.33 & $\mathbf{5 0 . 0 0}$ & - & 100.00 \\
\hline & St. Res.* & -1.5 & -2.2 & -1 & 0.3 & 9.6 & 18.8 & -0.1 & \\
\hline \multirow[t]{3}{*}{75} & $\mathrm{n}$ & - & - & - & - & - & - & 1 & 1 \\
\hline & $\%$ & - & - & - & - & - & - & 100.00 & 100.00 \\
\hline & St. Res.* & -0.6 & -0.9 & -0.4 & -0.4 & -0.1 & -0.1 & 26.7 & \\
\hline \multirow[t]{2}{*}{ Total } & $\mathrm{n}$ & 186 & 322 & 104 & 93 & 5 & 3 & 1 & 714 \\
\hline & $\%$ & 26.05 & 45.10 & 14.57 & 13.02 & 0.70 & 0.42 & 0.14 & 100.00 \\
\hline
\end{tabular}

*St. res.: standardized residual. McNemar-Bowker test $(p<0.001)$ and Kappa test $(p<0.001)=0.575$.

Similar results were observed in the NISS analysis. Table 5 shows that the percentages of agreement of the NISS scores were significant for each severity range, as indicated by the standardized residual values $(>1.96)$ and Kappa results, which indicated moderate agreement (0.543, $p<0.001)$.

The severity ranges with significant percentages of disagreement that were higher than the percentages of agreement were NISS 16 to 24 (51.32\%), 41 to 49 $(74.14 \%)$, and 50 to $74(80.00 \%)$. Disagreement in the NISS scores (McNemar to Bowker test $p<0.001$ ) was re- lated to the changes of scores classified by AIS-05 to lower severity ranges, except in ranges 1 to 8 (two cases), 16 to 24 (one case), and 25 to 40 (one case).

The percentage of deaths in patients with ISS scores $<16$ was significantly greater $(p<0.001)$ when using the 2005 version compared to the 1998 version: $22.90 \%$ versus $5.93 \%$, respectively. When the analysis was performed considering NISS scores $<16$, the percentage of deaths was also significantly higher with the 2005 version: $3.40 \%$ versus $2.54 \%(p<0.001)$. 
Table 5 - Distribution of NISS scores according to AIS-98 and AIS-05 versions and severity ranges. São Paulo - SP, 2005

\begin{tabular}{|c|c|c|c|c|c|c|c|c|c|}
\hline \multirow{2}{*}{ NISS 98} & & \multicolumn{7}{|c|}{$\begin{array}{l}\text { NISS } 05 \\
\end{array}$} & \multirow{2}{*}{ Total } \\
\hline & & 1 to 8 & 9 to 15 & 16 to 24 & 25 to 40 & 41 to 49 & 50 to 74 & 75 & \\
\hline \multirow[t]{3}{*}{1 to 8} & $\mathrm{n}$ & 145 & 2 & - & - & - & - & - & 147 \\
\hline & $\%$ & 98.64 & 1.36 & - & - & - & - & - & 100.00 \\
\hline & St. Res.* & 23.9 & -8.1 & -7.1 & -6.8 & -2.9 & -1.5 & -0.7 & \\
\hline \multirow[t]{3}{*}{9 to 15} & $\mathrm{n}$ & 24 & 123 & - & - & - & - & - & 147 \\
\hline & $\%$ & 16.33 & 83.67 & - & - & - & - & - & 100.00 \\
\hline & St. Res.* & -2.3 & 16.7 & -7.2 & -6.9 & -2.9 & -1.5 & -0.7 & \\
\hline \multirow[t]{3}{*}{16 to 24} & $\mathrm{n}$ & - & 77 & 74 & 1 & - & - & - & 152 \\
\hline & $\%$ & - & 50.66 & 48.68 & 0.66 & - & - & - & 100.00 \\
\hline & St. Res.* & -7.6 & 6.8 & 9 & -6.8 & -2.9 & -1.6 & -0.7 & \\
\hline \multirow[t]{3}{*}{25 to 40} & $\mathrm{n}$ & - & 1 & 78 & 88 & - & 1 & & 168 \\
\hline & $\%$ & - & 0.60 & 46.42 & 52.38 & & 0.60 & & 100.00 \\
\hline & St. Res.* & -8.2 & -9.2 & 8.9 & 11.8 & -3.2 & -0.9 & -0.8 & \\
\hline \multirow[t]{3}{*}{41 to 49} & $\mathrm{n}$ & - & - & 2 & 41 & 15 & - & - & 58 \\
\hline & $\%$ & - & - & 3.45 & 70.69 & 25.86 & - & - & 100.00 \\
\hline & St. Res.* & -4.4 & -5 & -3.5 & 9.9 & 8.4 & -0.9 & -0.4 & \\
\hline \multirow[t]{3}{*}{50 to 74} & $\mathrm{n}$ & - & - & 1 & 15 & 16 & 8 & - & 40 \\
\hline & $\%$ & - & - & 2.50 & 37.50 & 40.00 & 20.00 & - & 100.00 \\
\hline & St. Res.* & -3.6 & -4.1 & -3 & 2.8 & 11.4 & 10.9 & -0.3 & \\
\hline \multirow[t]{3}{*}{75} & $\mathrm{n}$ & - & - & - & - & - & - & 2 & 2 \\
\hline & $\%$ & - & - & - & - & - & - & 100.00 & 100.00 \\
\hline & St. Res.* & -0.8 & -0.9 & -0.7 & -0.7 & -0.3 & -0.2 & 26.6 & \\
\hline \multirow[t]{2}{*}{ Total } & $\mathrm{n}$ & 169 & 203 & 155 & 145 & 31 & 9 & 2 & 714 \\
\hline & $\%$ & 23.67 & 28.43 & 21.71 & 20.31 & 4.34 & 1.26 & 0.28 & 100.00 \\
\hline
\end{tabular}

*St. Res.: standardized residual. McNemar-Bowker test $(p<0.001)$ and Kappa test $(p<0.001)=0.543$.

\section{DISCUSSION}

Since its publication in 1971 by the Association for the Advancement of Automotive Medicine, AIS has been repeatedly revised and updated. The AIS-05 version included the most significant changes of the last 20 years $^{(15)}$.

In this study, the comparison of injury severity between the AIS-98 and AIS-05 versions found significant disagreements $(p<0.001)$ as well as substantial agreement (Kappa 0.748 ) between the scores (Table 1). The analysis showed decreased injury severity when using the 2005 version of AIS. The decrease in scores was greater in more severe injuries (AIS 3, 4, and 5).

The analysis of 109 patients with 602 traumatic injuries from two Australian hospitals showed a higher percentage of disagreement (28.20\%) of AIS scores than this study (18.10\%). In the Australian study, decreased AIS-05 scores were more frequent (26.20\%) compared to the 1998 version $^{(15)}$, which is similar to the results of this study.

In the analysis performed considering each body region, the differences observed in the mean AIS scores of the 1998 and 2005 versions were significant for the head, thorax, abdomen, and upper extremities, despite the small variation in absolute values. The most significant changes were related to the injury severity scores. When analyzing head injuries, changes in the severity level were observed with decreases in AIS from 4 to 3 in various types of injury. Epidural, subdural, and intracerebral hematomas without other specifications regarding extension and volume that were classified as AIS 4 in the 1998 version became classified as AIS 3. Intraventricular hemorrhages, classified as score 4 in AIS-98, became score 2 in AIS-05. Subarachnoid hemorrhage, classified as score 3 in AIS-98, also became score 2 in the 2005 version $^{(6-7)}$. In this sample, the occurrence of these types of injuries was high, and thus a reduction in the injury severity score was often observed. Similar results were observed in an American study that analyzed blunt injuries of the head region coded according to AIS-98 and AIS-05. The AIS and Maximum AIS (MAIS) scores of the head region were significantly lower in the 2005 version $^{(16)}$.

In the thoracic region, the number of injuries varied in the AIS-98 and AIS-05 versions, totaling 225 and 254, respectively. When analyzing body regions, the thorax is not the region with the highest number of injuries, but their occurrence is related to high morbidity and mortality ${ }^{(17)}$. It is important to highlight the difficulties found when processing the thoracic region analysis due to the new coding rules presented in the AIS-05 manual. In the previous version, in the presence of pneumothorax or hemothorax, rib fractures were scored with a single score, and the same applied to lung lacerations associated with hemothorax, simple or tension pneumothorax, hemomediastinum, or pneumomediastinum $^{(6)}$. In 2005, these injuries were classified separately, which increased the number of scores related to the thoracic region ${ }^{(7)}$. This difference made the 
analysis difficult because the number of AIS scores in the thoracic region differed between the two versions; i.e., certain injuries did not have corresponding scores in the 1998 version. The analysis of the AIS-98 and AIS-05 versions by Kappa (Table 1) did not include these injuries due to the lack of a corresponding score in the 1998 version.

In the Australian study mentioned above, 24 injuries were scored only with the AIS-05 version, 13 of which were related to thoracic injuries. Therefore, in this study, the analysis was performed based only on injuries with corresponding scores in both versions. The percentage of agreement of AIS scores in the thoracic region was $41.20 \%$. Regarding the head region, the percentage of agreement was $63.70 \%$. Therefore, this study showed significant changes in the AIS scores of the head and thoracic region ${ }^{(15)}$.

In another study on the 1998 and 2005 versions that included 2,250 patients from two U.S. hospitals, the body regions with more coding changes were the extremities $(54.70 \%)$, followed by the thorax (18.50\%) and head $(14.70 \%)^{(18)}$. The high frequency of coding changes for extremities ${ }^{(18)}$ differed from the results observed in the Australian study ${ }^{(15)}$. This result may be related to decreased trauma severity in patients from the U.S. study, as approximately $70.00 \%$ of them were classified as ISS $<16^{(18)}$. The authors themselves recognize limitations related to population differences between patients from the two hospitals included in the analysis. Thus, the differences observed in scores assigned to injuries in the extremities of patients may be related to specific AIS codes, which underwent a greater number of changes in the new manual ${ }^{(18)}$

Although several injuries were classified with greater severity in the 2005 manual, these changes did not significantly affect the overall evaluation of certain body regions, and it is important to mention that most of these injuries are uncommon injuries. In the studied sample, the AIS scores were higher with the 2005 version in only $19(0.64 \%)$ of the total 2,970 injuries.

In this study, comparisons between the ISS and NISS calculated using the 1998 and 2005 AIS versions showed a significant decrease in these scores, similar to the results observed when analyzing AIS scores. Despite the high percentages of disagreement observed in data from Tables 4 and 5, varying degrees of agreement were confirmed using the Kappa test. Similar to this study, the analysis of 109 Australian patients and 2,250 American patients also showed decreased ISS and NISS values ${ }^{(15,18)}$. In the Australian study, a decrease of up to 22 points in ISS and up to 32 points in NISS was observed with AIS-05 ${ }^{(15)}$. Decreased mean ISS and NISS values of the 2,250 patients were also observed with AIS-05 for the U.S. study ${ }^{(18)}$.

When assigning ISS and NISS according to AIS-98 and AIS-05, in the death group, there was an increase in the percentage mortality for lower ISS and NISS values in the AIS-05 version. The analyses of trauma severity levels considering ISS and NISS $<16$ showed a lower percentage of mortality (5.93\% and $2.54 \%$, respectively) when they were based on AIS-98. When AIS-05 was used, the frequency of deaths was higher, with $22.90 \%$ for ISS and $3.40 \%$ for NISS. Thus, the percentage mortality increased in ISS and NISS scores $<16$ with the 05 version.

Since 1988, the categorization of ISS scores proposed by researchers ${ }^{(8)}$ has been used to analyze trauma severity based on the ISS 16, which is indicative of greater severity trauma and mortality of approximately $10 \%^{(8,19)}$. Data from the American National Trauma Data Bank regarding 2008 showed a mortality rate of $6.56 \%$ for patients with ISS from 16 to $24^{(20)}$. This evidence indicates an expected situation, considering the technological and scientific advances that occurred in the 20 years after the U.S. study was published $^{(19)}$. The results described here indicate that the classification proposed in $1988^{(8)}$ does not apply to AIS-05; i.e., to use AIS-05, these ranges need to be revised so that they are compatible with all modifications. Thus, the comparison of populations coded by AIS- 05 with populations coded by previous versions should consider the updates in the AIS-05 version.

Another issue to be considered is the impact on international trauma centers. The financial support for pre-hospital, hospital, and rehabilitation services is distributed annually to U.S. trauma centers according to their designated level of care, location, and volume of patients ${ }^{(18,21)}$, based on ISS $>12$ for adult patients or ISS $>8$ for children ${ }^{(18)}$. The adoption of the 2005 version will result in decreased ISS values and consequently lower financial funds for these institutions. The trauma center level assigned by the American College of Surgeons is based on the number of admissions and treatments of patients with ISS $>15^{(18,22)}$. Thus, the adoption of the 2005 version may interfere with the designation and accreditation of these centers ${ }^{(18,23)}$. The databases can be modified to allow this adjustment based on code mappings between the two versions ${ }^{(15)}$ or, as suggested by another author, data can be manually coded with independent analyses $^{(18)}$. However, these practices require additional cost and time.

It is important to note that the AIS-98 version is an index developed years ago, in contrast to the 2005 publication, which was revised to be current regarding terminology, diagnosis and prognosis.

However, considering this study, particularly the results that concern the distribution of frequency of deaths according to ISS and NISS values, one can conclude that the increased mortality with ISS $<16$ in the AIS-05 version occurred because these patients had significant injuries that resulted in death, although these patients were classified as of low severity (ISS <16).

The performance analysis of tools such as AIS, ISS, and NISS contributes to the improvement of these instruments, which can be used to evaluate the quality of trauma care. 
The analysis of the care results considering trauma severity is essential given the high number of patients in the trauma care system. The use of AIS, ISS and NISS can support, for example, the analysis of the number of patients considering the hierarchy and regionalization of health services in providing resources and in quantifying and qualifying the multidisciplinary healthcare team. In this context, the nurse stands out in all phases of care provision.

This study exhibited some limitations, such as small sample size, which made it difficult to analyze groups of patients defined according to mechanisms of trauma, and the use of secondary data to obtain descriptions of the injuries. Therefore, further analysis would be desirable concerning the trauma severity (MAIS, ISS, and NISS), age extremes, and mechanisms of trauma on a larger number of patients.

In contrast to the AIS-98 and AIS-05 versions, when updating the 2005 manual for the 2008 version, few modifications were included. Changes were related to the

\section{REFERENCES}

1. Skaga NO, Eken T, Hestnes M, Jones JM, Steen PA. Scoring of anatomic injury after trauma: AIS 98 versus AIS $90-$ do the changes affect overall severity assessment? Injury. 2007;38(1):84-90.

2. Stevenson M, Segui-Gomez M, Lescohier I, Di Scala C, McDonald-Smith G. An overview of the Injury Severity Score and the New Injury Severity Score. Inj Prev. $2001 ; 7(1): 10-3$.

3. Gennarelli TA, Wodzin E. AIS 2005: a contemporary injury scale. J Injury. 2006;37(12):1083-91.

4. Committee on Medical Aspects of Automotive Safety. Rating the severity of tissue damage. I. The Abbreviated Scale. JAMA. $1971 ; 215(2): 277-80$.

5. Osler T, Baker SP, Long W. A modification of the Injury Severity Score that both improves accuracy and simplifies scoring. J Trauma. 1997;43(6):922-5.

6. Association for the Advancement of Automotive Medicine. The Abbreviated Injury Scale (AIS): 1990 revision, update 1998. Illinois: Des Plaines; 1998.

7. Association for the Advancement of Automotive Medicine. The Abbreviated Injury Scale (AIS). Illinois: Des Plaines 2005.

8. Copes WS, Champion HR, Sacco WJ, Lawnick MM, Keast SL, Bain LW. The Injury Severity Score revisited. J Trauma. 1988;28(1):69-77.

9. Baker SP, O'Neill B, Haddon W Jr, Long WB. The Injury Severity Score: a method for describing patients with multiple injuries and evaluating emergency care. J Trauma. 1974;14(3):187-96. inclusion of certain specific injuries and refinement of the description of other injuries, and this update does not affect the results presented here ${ }^{(24-25)}$.

\section{CONCLUSION}

We conclude that the agreement between scores assigned to injuries coded by AIS-98 and AIS-05 was greater than $60 \%$, except for severe injuries (AIS 4). However, there was also disagreement, with decreased injury severity, especially for severe lesions, when the 2005 version was used. The injury severity determined by the 2005 version was lower in the head, thorax, abdomen, and upper extremities compared with the 1998 version. The ISS and NISS values obtained with AIS-05 showed a reduction in injury severity, especially in the ranges from 16 to 24,41 to 49 , and 50-74. The percentage mortality was higher in ISS and NISS <16 when using the 2005 version.

10. Domingues CA, Sousa RMC, Nogueira LS, Poggetti RS, Fontes B, Munõz D. The role of the New Trauma and Injury Severity Score (NTRISS) for survival prediction. Rev Esc Enferm USP [Internet]. 2011 [cited 2013 Oct 10];45(6):135055. Available from: http://www.scielo.br/pdf/reeusp/ v45n6/en_v45n6a11.pdf

11. Siegel S, Castellan NJ. Nonparametric statistics. New York: McGraw-Hill; 1988.

12. Fleiss JL. Statistical methods for rates and proportions. New York: John Wiley; 1981.

13. Landis JR, Koch GG. The measurement of observer agreement for categorical data. Biometrics. 1977;33(1):159-74.

14. Pereira JCR. Análise de dados qualitativos. São Paulo: EDUSP; 1999.

15. Palmer CS, Niggemeyer LE, Charman D. Double coding and mapping using Abbreviated Injury Scale 1998 and 2005: identifying issues for trauma data. Injury. 2010;41(9):830-6.

16. Carroll CP, Cochran JA, Price JP, Guse CE, Wang MC. The AIS-2005 revision in severe traumatic brain injury: mission accomplished or problems for future research? Ann Adv Automot Med. 2010;54:233-8.

17. Calil AM, Sallum EA, Domingues CA, Nogueira LS. Mapping injuries in traffic accident victims: a literature review. Rev Latino Am Enferm. 2009;17(1):120-5.

18. Salottolo K, Settell A, Uribe P, Akin S, Slone DS, O'Neal $E$, et al. The impact of the AIS 2005 revision on injury severity scores and clinical outcome measures. Injury. 2009;40(9):999-1003. 
19. Boyd CR, Tolson MA, Copes WS. Evaluating trauma care: the TRISS method. J Trauma. 1987;27(4):370-8.

20. American College of Surgeons. National Trauma Data Bank 2008. Annual Report. Version 8.0 [Internet]. 2008 [cited 2010 Oct 11]. Available from: http://www.facs.org/trauma/ ntdb/pdf/ntdbannualreport2008.pdf

21. Kuwabara K, Matsuda S, Imanaka Y, Fushimi K, Hashimoto $H$, Ishikawa $K B$, et al. Injury Severity Score, resource use, and outcome for trauma patients within a Japanese Administrative Database. J Trauma. 2010;68(2):463-70.

22. American College of Surgeons; Committee on Trauma. Resources for optimal care of the injured patient, 2014 [Internet]. Chicago; 2014 [cited 2014 May 30]. Available from: http://www.facs.org/trauma/verification/resourcespreview/resources.pdf
23. Stewart KE, Cowan LD, Thompson DM. Changing to AIS 2005 and agreement of injury severity scores in a trauma registry with scores based on manual chart review. Injury. 2010;42(9):934-9.

24. Ringdal KG, Hestnes $M$, Palmer CS. Differences and discrepancies between 2005 and 2008 Abbreviated Injury Scale versions: time to standardize. Scand J Trauma Resusc Emerg Med. 2012,20:11.

25. Palmer CS, Hestnes M, Ringdal KG. Summary of changes made between Abbreviated Injury Scale 2005 and Abbreviated Injury Scale 2005 - Update 2008 [Internet]. [cited 2013 July 2]. Available from: http://www.rch.org.au/ uploadedFiles/Main/Content/paed_trauma/AIS05-AIS08_ changes.pdf
Correspondence addressed to: Maria Carolina Barbosa Teixeira Lopes Rua Napoleão de Barros, 754 - $2^{\circ}$ andar - sala 206 - Vila Clementino CEP 04024-002 - São Paulo, SP, Brazil E-mail: carol-lopes@ig.com.br 